\title{
Study of Surface Roughness and Burr Formation After Milling of Carbon Fiber/Titanium Stacks
}

\author{
Tarik Hazem Ashmawi ${ }^{a} \oplus$, Guilherme Wolf Lebrã ${ }^{a}$, Susana Marraccini Giampietri Lebrã ${ }^{a}{ }^{*} \odot$, \\ Éd Claudio Bordinassi ${ }^{(\mathbb{C})}$ \\ anstituto de Tecnologia Mauá, São Caetano do Sul, SP, Brasil.
}

Received: June 17, 2019; Revised: December 19, 2019; Accepted: January 10, 2020

\begin{abstract}
This work aims to study the influence of cutting parameters (cutting speed, feed rate, cutting depth and tool cutting edge angle) regarding surface roughness and burr formation during the milling of a mixed structure comprised of titanium and carbon fiber (stack). The parameters were varied from maximum to minimum, just as the tool cutting edge angle of the insert, through a full factorial design with 32 trials. The analyses were performed by measuring the surface roughness and burr size along with metallographic analyses through optic microscopy and scanning electron microscopy. The results showed that the surface roughness was higher for carbon fiber and burr size was higher for titanium. There were a number of tests with delamination of the carbon fiber, and the best cutting parameters to minimize surface roughness and burr formation were tool cutting edge angle of $45^{\circ}$, a feed rate of $0.028 \mathrm{~mm} /$ tooth, cutting depth equal to $0.26 \mathrm{~mm}$ and cutting speed equal to $150 \mathrm{~m} / \mathrm{min}$.
\end{abstract}

Keywords: Burr size, surface roughness, stack, titanium, carbon fiber, milling.

\section{Introduction}

The aviation industry has possessed strong value over the world since it intensified the integration among civilizations when along the $20^{\text {th }}$ century and in the early $21^{\text {st }}$ century, a large demand for aircraft with higher performance and lesser weight occurred, which is predicted to last for the next 20 years. ${ }^{1}$ The first airplanes were built with fabric and wood at the beginning of the $20^{\text {th }}$ century thanks to the works by Alberto Santos Dumont and by the Wright brothers, Wilbur and Orville. In 1916, the German company Junkers produced a metal prototype that, albeit never approved for take-off, was fundamental for integrating this material to plane's fuselage. Starting in the 1960s, polymeric materials with greater emphasis on carbon fiber were introduced in the development of planes, due to the mass reduction of their pieces, but accommodating the flight requirements for the crafts. ${ }^{2}$ These materials began to be used together to strengthen their properties.

Two materials to be highlighted in this section, thanks to their qualities, are titanium and carbon fiber. In aircraft, carbon fiber reinforced composites or carbon fiber reinforced polymers (CFRP) compose a large part of the fuselage, drastically reducing mass. The main benefit is fuel consumption reduction with the same capability for load transportation. ${ }^{3}$ Titanium is introduced in regions requiring metallic parts and temperature resistance, such as the fuselage and parts of the motor. On the other hand, both materials can be used together to form high performance structures such that they compensate for each other's properties. ${ }^{4}$ These structures are denominated stacks: two joined boards, a titanium one and a carbon fiber one. The advantages of this combination are galvanic corrosion reduction, higher specific strength and lower burr formation. ${ }^{3}$

The machining and, specifically, milling of these boards, however, are extremely delicate, since both components have a series of setbacks related to these processes.

*e-mail: susana.lebrao@maua.br
The mechanical trimming of titanium is known to have a very difficult execution with a short duration of the tools. Even though it requires low cutting forces and low energy consumption when compared to other metals, like iron, nickel or even copper, especially in the low-speed range, the working tools suffer a reduction of service life. This fact derives from the small cutting contact between race face and the material during machining, generating high compressing tensions upon the insert, causing premature wear. ${ }^{5}$ Furthermore, the heat generated along the cutting zone during machining should be considered, due to the friction between the material and the tool, and high deformation rates, increasing cutting forces. As a consequence of poor thermal conduction, the heat is not dissipated to the rest of the material and the cutting forces are concentrated on the trimming region, creating hostile conditions for material cutting and benefiting tool wear ${ }^{5}$. Milling composite materials is a rather complex task owing to its heterogeneity and the number of problems, such as surface delamination, that appear during the machining process, associated with the characteristics of the material and the cutting parameters ${ }^{6}$.

The low machinability of CFRP composite materials generally leads to various machining failures including delamination, burrs, and subsurface failures ${ }^{7}$. The main problem in the carbon fiber, while under machining, suffers a process called delamination. ${ }^{3,4,8}$ Delamination is the separation of the fiber layers, caused by the combined effects of the axial force and machine torque during machining 9 . This phenomenon considerably reduces fatigue resistance and material quality regarding dimensional and geometrical tolerance. ${ }^{9}$ The delamination occurring in the superior region of the piece is called "peel-up" delamination and "push-out" delamination in the inferior one. This issue, added to the complexity of fiber orientation in the piece, requires the preparation of a complex fixation system for machining. ${ }^{8}$ 
Besides delamination, the burr is another great problem during the machining of CFRP, according to Kurniawan et al. ${ }^{10}$, a burr is an undesired material that remains along the machined edge of material and it cannot be easily removed, so is desirable during machining obtain pieces with small burrs.

An important aspect of tool and workpiece geometry is the exit order of the tool edges because the burr appears near the final exit position of the tool along the workpiece edge. The exit order of the tool may greatly influence the burr formation in terms of burr position on the workpiece in face milling ${ }^{11}$. Many researches were conducted to study burr formation, Hashimura et al. ${ }^{11}$ for example, studied the burr formation in milling with many tools varying mainly the In-plane exit, axial and radial rake angle. They concluded that the exit order of cutting toot edges is an important factor to determine the burr size. Aurich et al. ${ }^{12}$ proposed a schematic sequence for burr formation: continuous cutting, pre-initiation, initiation, pivoting, burr development, after this, depending on the kind of material two ways are possible: a) brittle materials: crack initiation, crack growth, negative burr (break-out), b) ductile materials: crack initiation, crack growth, positive burr. Many variables influence the burr formation, like, material, tool geometry and characteristic, machining operation and position, so its important to conduct studies in this area.

The surface roughness also has great importance in the machined surfaces and has a significant influence on fatigue life, creep, corrosion, and dimensional accuracy of a machined component ${ }^{13}$. The surface quality depends on the cutting parameters, tool geometry and cutting forces and the correct selection of cutting parameters is essential in the machining of polymer matrix composites ${ }^{7}$. According to Erkan ${ }^{14}$, the surface measurement results indicate that surface roughness was improved with increasing cutting speed whereas it deteriorated with increasing feed rate in the carbon fiber machining. These results also are traditional in the metal machining of steels and steel alloys. The emerging minimization of such surface defects, minimum tool wear and minimum surface roughness in the processing of carbon fibers are among the issues targeted by the many researchers ${ }^{6}$.

The main goal of this work is to understand the behavior of the cutting parameters during milling of a titanium/carbon fiber stack, varying cutting speed, cutting depth, feed rate and working tool cutting edge angles, on the burr formation and surface roughness.

\section{Experimental}

\subsection{Materials}

The stack used in this work is composed of a titanium bond Ti-6Al-4V with dimensions of $130 \mathrm{~mm}$ x $300 \mathrm{~mm}$ and $7 \mathrm{~mm}$ thickness, and a CFRP multidirectional rolled made up of graphite and epoxy matrix, reinforced with carbon fiber fabric (8HS, Plain Weave), glass (7781/8HS, 116/Plain) and aramid (Kevlar 285-4HS, 220-Plain) with dimensions of $130 \mathrm{~mm} \times 300 \mathrm{~mm}$ and $6.5 \mathrm{~mm}$ thickness ${ }^{15}$. Both boards were glued by a bi-component adhesive produced by manufacturer Lord; Fusor 380NS and 383NS, the basis of which are, respectively, modified epoxy resins and amines.

\subsection{Procedures}

The board was cut into small sample parts of a width of $24 \mathrm{~mm}$ and length of $27 \mathrm{~mm}$. The equipment used was a horizontal band saw of the Ronemak brand, MR $210 \mathrm{G}$ model. The original board was divided into 44 sample parts.

The milling process occurred at a Sandvik Coromant Productivity Center in São Paulo. The equipment used was a machining center D800 model from the Romi brand, presenting a command developed by Siemens, model 828D. The milling inserts used were R245-12 T3 E-ML 1040 and R390-11 T3 64M-PM 1130, both made of cemented carbide with PVD (Ti, Al) N2 as coating and tool cutting edge angles of $45^{\circ}$ and $90^{\circ}$, respectively. The holder tools were R245063Q22-12M and R390-020A20-11M, containing 5 and 3 inserts, respectively. The number of trials was calculated through a full factorial design of $2^{5}$ with five being the number of variables. These variables are cutting speed $\left(\mathrm{v}_{\mathrm{c}}\right)$ $=150 \mathrm{~m} / \mathrm{min}$ and $180 \mathrm{~m} / \mathrm{min}$, cutting depth $\left(\mathrm{a}_{\mathrm{p}}\right)=0.25 \mathrm{~mm}$ and $0.5 \mathrm{~mm}$, feed rate (f) $=0.02 \mathrm{~mm} /$ tooth and $0.04 \mathrm{~mm} /$ tooth, tool cutting edge angle of $90^{\circ}$ and $45^{\circ}$ and the region (titanium or carbon fiber) containing resulting burr due to the removal of the insert tool from the sample piece. The procedure consisted of a pass perpendicular to both halves of the piece so that they were simultaneously milled.

The measurements of the sample pieces surface roughness and burr size were carried out at the metrology laboratory at the Mauá Institute of Technology, São Caetano do Sul. The equipment used was a SJ 201 Mitutoyo rugosimeter (surface roughness), a PJ-300H Mitutoyo profile projector and digital grasshopper gage Mitutoyo (burr size). The surface roughness was measured according to the ABNT NBR 8404. During the surface roughness measurement, three measurements were made for each sample piece and their mean was recorded.

Figure 1 shows a milled sample.

The preparation process for the metallographic specimen was carried out at the Metallography Laboratory of the Mauá Institute of Technology in São Caetano do Sul and aimed at analyzing the burr formed on the titanium and carbon fiber using optical microscopy. The standard used was ABNT NBR 13284. The four pieces selected for analysis in the microscope had been submitted to milling with a tool cutting edge angle of $90^{\circ}$ : one pair milled with the highest cutting parameters and the other with the lowest. The pieces belonged to trial numbers 17, 24, 25 and 32 in the first column of Table 1. 


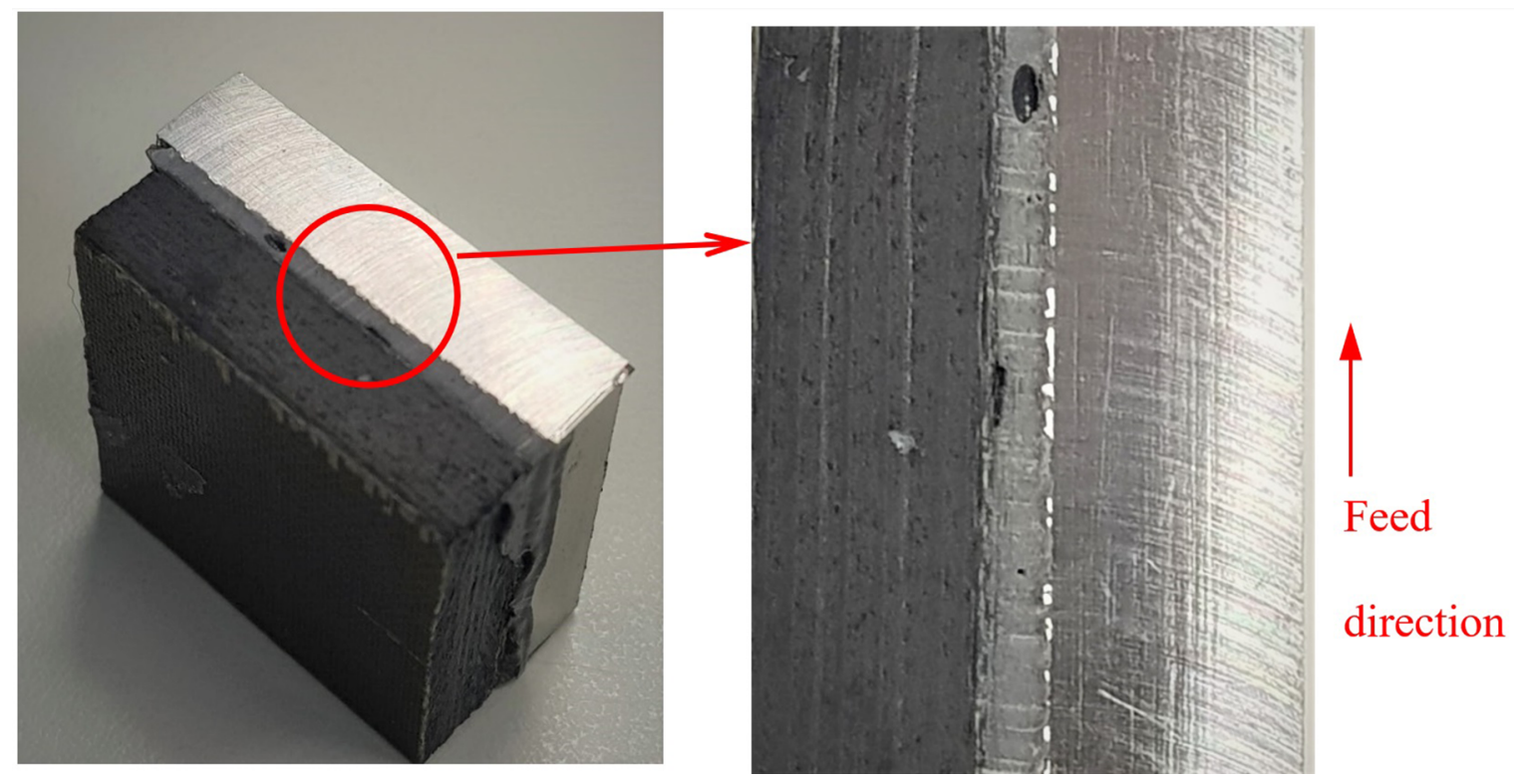

Figure 1. Milled sample

Table 1. Results

\begin{tabular}{|c|c|c|c|c|c|c|c|c|c|}
\hline Trial & $\begin{array}{c}\mathrm{vc} \\
(\mathrm{m} / \mathrm{min})\end{array}$ & $\begin{array}{c}f \\
(\mathrm{~mm} / \text { tooth})\end{array}$ & ap (mm) & $\begin{array}{c}\text { region } \\
\text { with burr } \\
\text { formation }\end{array}$ & $\begin{array}{l}\text { tool cutting } \\
\text { edge angle (o) }\end{array}$ & $\begin{array}{c}\text { surface } \\
\text { roughness } \mathrm{Ti} \\
(\mu \mathrm{m})\end{array}$ & $\begin{array}{c}\text { surface } \\
\text { roughness } \\
\text { CRFP }(\mu \mathrm{m})\end{array}$ & $\begin{array}{c}\text { mean surface } \\
\text { roughness } \\
(\mu \mathrm{m})\end{array}$ & $\begin{array}{c}\text { burr size } \\
(\mu \mathrm{m})\end{array}$ \\
\hline 1 & 150 & 0.02 & 0.25 & carbon & 45 & 0.1183 & 0.3800 & 0.5300 & 38.00 \\
\hline 2 & 180 & 0.02 & 0.25 & carbon & 45 & 0.1283 & 0.5425 & 0.5725 & 80.00 \\
\hline 3 & 150 & 0.04 & 0.25 & carbon & 45 & 0.1017 & 0.8333 & 0.8500 & 85.00 \\
\hline 4 & 180 & 0.04 & 0.25 & carbon & 45 & 0.0917 & 0.4225 & 1.2633 & 127.00 \\
\hline 5 & 150 & 0.02 & 0.5 & carbon & 45 & 0.1133 & 1.2267 & 1.1417 & 182.50 \\
\hline 6 & 180 & 0.02 & 0.5 & carbon & 45 & 0.1200 & 1.2500 & 1.4490 & 95.00 \\
\hline 7 & 150 & 0.04 & 0.5 & carbon & 45 & 0.1750 & 1.2267 & 1.2800 & 100.00 \\
\hline 8 & 180 & 0.04 & 0.5 & carbon & 45 & 0.1367 & 1.1740 & 1.2300 & 95.00 \\
\hline 9 & 150 & 0.02 & 0.25 & titanium & 45 & 0.1050 & 1.4100 & 0.1117 & 95.00 \\
\hline 10 & 180 & 0.02 & 0.25 & titanium & 45 & 0.1700 & 0.8750 & 0.1492 & 66.50 \\
\hline 11 & 150 & 0.04 & 0.25 & titanium & 45 & 0.1100 & 1.1083 & 0.1058 & 120.00 \\
\hline 12 & 180 & 0.04 & 0.25 & titanium & 45 & 0.1567 & 1.3450 & 0.1242 & 2680.00 \\
\hline 13 & 150 & 0.02 & 0.5 & titanium & 45 & 0.1250 & 1.0567 & 0.1192 & 140.00 \\
\hline 14 & 180 & 0.02 & 0.5 & titanium & 45 & 0.1283 & 1.5817 & 0.1242 & 167.50 \\
\hline 15 & 150 & 0.04 & 0.5 & titanium & 45 & 0.1750 & 1.3333 & 0.1750 & 85.00 \\
\hline 16 & 180 & 0.04 & 0.5 & titanium & 45 & 0.2583 & 0.4625 & 0.1975 & 135.00 \\
\hline 17 & 150 & 0.02 & 0.25 & carbon & 90 & 0.3683 & 1.5700 & 1.0875 & 167.00 \\
\hline 18 & 180 & 0.02 & 0.25 & carbon & 90 & 0.4433 & 1.0717 & 0.8913 & 100.00 \\
\hline 19 & 150 & 0.04 & 0.25 & carbon & 90 & 0.5800 & 1.1133 & 1.0025 & 205.00 \\
\hline 20 & 180 & 0.04 & 0.25 & carbon & 90 & 0.3933 & 1.1950 & 1.1000 & 160.00 \\
\hline 21 & 150 & 0.02 & 0.5 & carbon & 90 & 0.2050 & 0.9900 & 0.9517 & 200.00 \\
\hline 22 & 180 & 0.02 & 0.5 & carbon & 90 & 0.2533 & 0.9467 & 1.0213 & 210.00 \\
\hline 23 & 150 & 0.04 & 0.5 & carbon & 90 & 0.4383 & 0.9183 & 0.9643 & 108.00 \\
\hline 24 & 180 & 0.04 & 0.5 & carbon & 90 & 0.3383 & 1.0950 & 1.5267 & 130.00 \\
\hline 25 & 150 & 0.02 & 0.25 & titanium & 90 & 0.3100 & 1.1525 & 0.3392 & 395.00 \\
\hline 26 & 180 & 0.02 & 0.25 & titanium & 90 & 0.2317 & 0.8100 & 0.2670 & 922.50 \\
\hline 27 & 150 & 0.04 & 0.25 & titanium & 90 & 0.4250 & 1.1433 & 0.4363 & 378.00 \\
\hline 28 & 180 & 0.04 & 0.25 & titanium & 90 & 0.4217 & 1.0050 & 0.4075 & 325.00 \\
\hline 29 & 150 & 0.02 & 0.5 & titanium & 90 & 0.3500 & 0.9133 & 0.2775 & 864.00 \\
\hline 30 & 180 & 0.02 & 0.5 & titanium & 90 & 0.3367 & 1.3240 & 0.2950 & 969.00 \\
\hline 31 & 150 & 0.04 & 0.5 & titanium & 90 & 0.3667 & 1.4300 & 0.4025 & 972.50 \\
\hline 32 & 180 & 0.04 & 0.5 & titanium & 90 & 0.4250 & 1.6517 & 0.3817 & 935.00 \\
\hline
\end{tabular}


The four pieces were cut in half using a cut-off machine made by Arotec, model COR-40 and both halves were mounted with the use of a Struers-made mounting press, model Prestopress- 3 containing Bakelite. Then the pieces were sanded with a mechanical sander and four sandpapers of 220,320, 400 and 600 mesh. The pieces were then sanded with a mechanical polishing machine model Panambra DP 9 from Struers manufacturer along with diamond paste, whose particle size was $6 \mu \mathrm{m}$; and cloth $(\varnothing=200 \mathrm{~mm})$ from Struers; and another mechanical polishing machine from Struers, model Panambra DP 9 along with alumina with particle size of $1 \mu \mathrm{m}$ and cloth $(\varnothing=200 \mathrm{~mm})$ from Stuers.

The last stage of the metallographic specimen preparation involved the immersion of the four samples into a mixture containing $95 \mathrm{~mL}$ of distilled water, $3 \mathrm{~mL}$ of nitric acid $\left(\mathrm{HNO}_{3}\right)$ and $2 \mathrm{~mL}$ of hydrofluoric acid (HF). All the pieces were analyzed in an optical microscope by Olympus, model BX60M with an optic tube composed of the parts models UC30, U-CMAD-2 and U-TVO5X.
Analyses using a scanning electron microscope were performed in the Laboratory of Recycling, Residue Treatment and Extraction at the University of São Paulo. The equipment used was made by Phenom, model Pro X. The four pieces selected had been submitted to milling with a tool cutting edge angle of $45^{\circ}$ : one pair milled with the highest cutting parameters and the other with the lowest. The pieces belonged to trial numbers $1,8,9$ and 16 .

\section{Results and Discussion}

The results originated from the measurements of surface roughness and burr size for all thirty-two trials are shown in Table 1.

Firstly, Pareto charts for the burrs size and surface roughness of both materials were made to evaluate the statistical significance of each parameter as shown in Figure 2. The material where burrs were formed caused the highest influence over surface roughness and burrs size, which was much more distinct from the others.

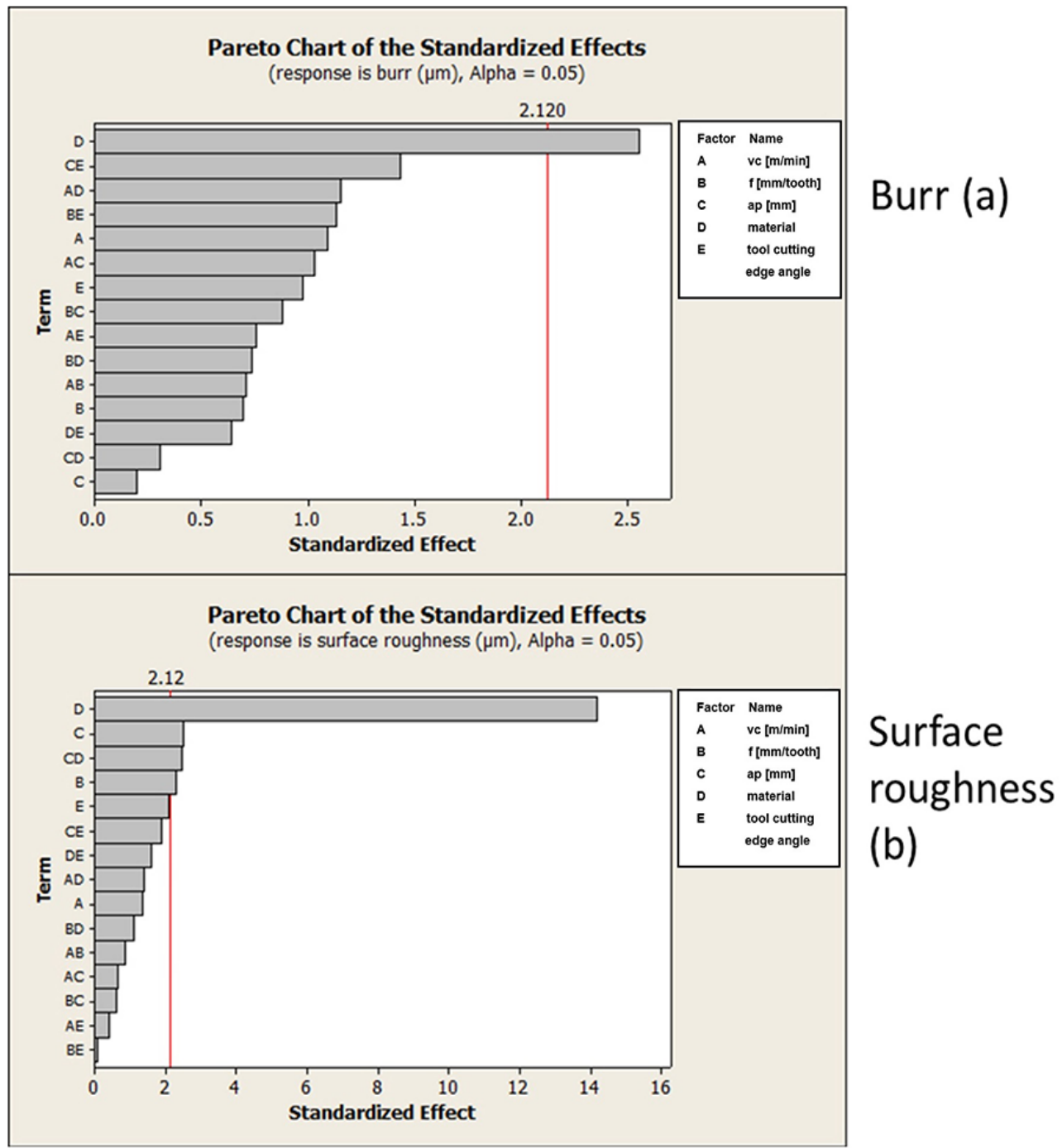

Figure 2. Pareto charts of burrs size sand surface roughness for both materials 
This is easily justified by the huge differences between both materials, the titanium is a ductile material and the machinability of the carbon fiber has high hardness and abrasiveness (at times even harder than some of the tool materials), due to their brittle nature, consequently, the burr formation in these materials are very distinct. In the case of roughness surface, the effects of cutting depth, material and depth combined and feed rate showed a slight statistical significance.

Figure 3 displays the interaction graphs among the effects of the cutting parameters, tool and material over surface roughness (b) and burrs (a). The average burr size for titanium is bigger than carbon fiber $(578.125 \mu \mathrm{m}$ in comparison to $130.156 \mu \mathrm{m}$, around 4.5 times over), whereas the opposite occurred to surface roughness: the observed average value for carbon fiber was $1.05 \mu \mathrm{m}$, while 0.24 for titanium (approximately 4.3 times lower).

A possible explanation for these phenomena is the carbon fibers low shear stress resistance, causing them to be easily machined and having small and brittle swarf and burrs, whereas its surface roughness is high due to the material being fibrous and non-homogenous.
Moreover, whilst milling, the possibility of cracking propagation exists for the fibers, due to the fragility of the materials. Titanium, on the other hand, is a metal with a high shear-strain rate and high ductility allowing a larger size for its swarf and burrs, besides creating a better surface finish (lower surface roughness). However, the values for surface roughness and burr sizes for carbon fiber and titanium are strongly affected by cutting parameters and preclude widespread conclusions.

Graphs E, F and G from Figure 3(a) are in accordance with results from Kumar et al. ${ }^{16}$, Thepsonthi and Özel ${ }^{17}$ and Thepsonthi and Özel ${ }^{18}$; which assert that smaller feed rates generate better surface finishes on the piece for micro-milling. The same resuls are also obtained by Ali et al. ${ }^{19}$, Karkalos, Galanis, Markopoulos ${ }^{20}$, and Shokrani, Dhokia, Newman ${ }^{21}$, since the since the roughness are geometrically dependent of feed rate.

Note the occurrence of a crossword in the graph I from Figure 3(b): considering a cutting depth of 0.5 $\mathrm{mm}$, the average burr size increases with the tool cutting edge angle, while it decreases with the increase of tool cutting edge angle for a cutting depth of $0.25 \mathrm{~mm}$.

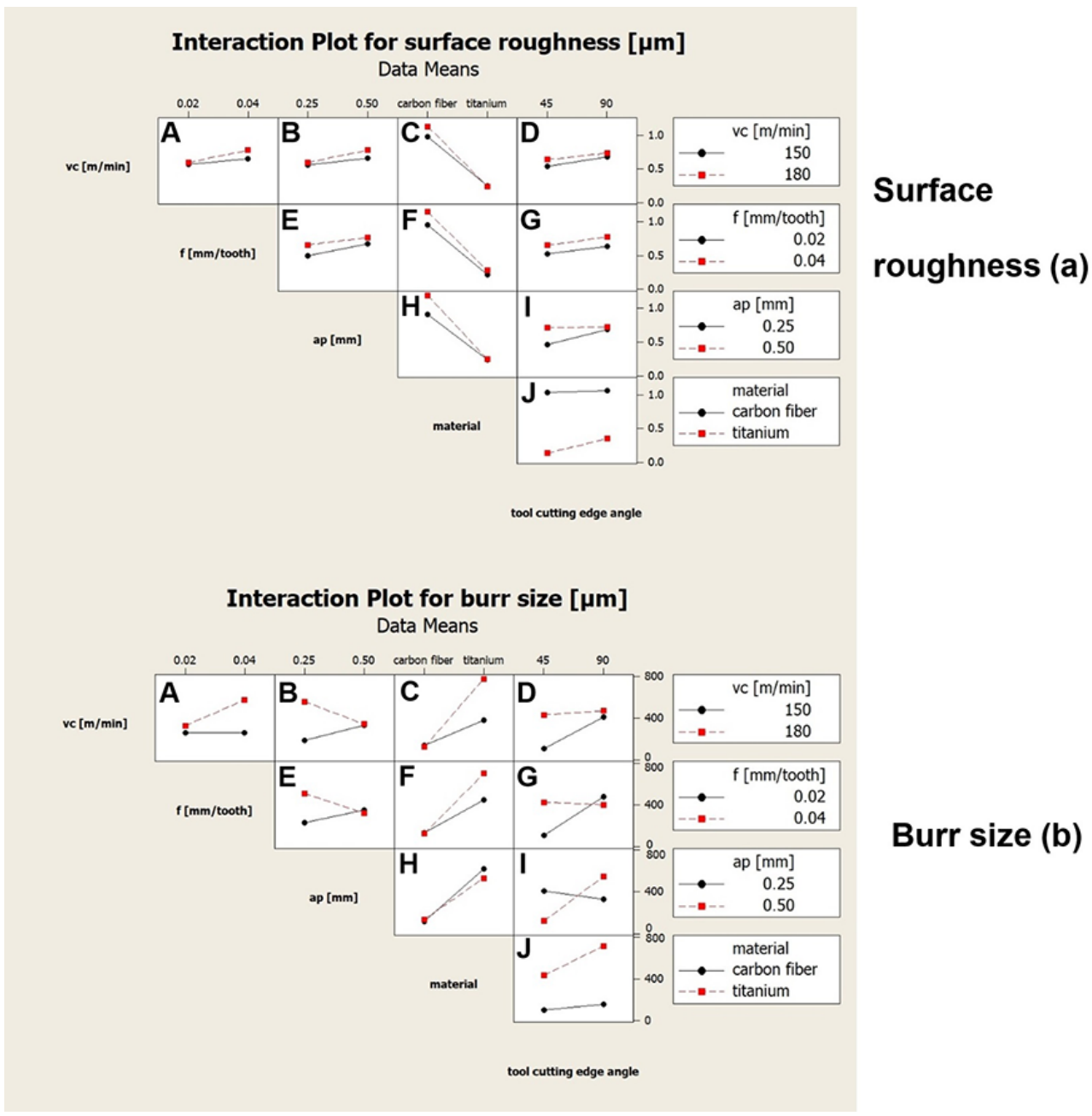

Figure 3. Interactions graphs between the factors over surface roughness and burrs 
The pivoting point of burr size with higher cutting depth, mainly in the titanium and the tool cutting edge $=90^{\circ}$, promote bigger burrs by the formation of the material since the burrs were not removed by the tool nose point. In the case of tool cutting edge $=45^{\circ}$, smaller burrs were formed by the inclination of the main edge tool.

Pareto charts displayed in Figure 4 were made for the burrs and surface roughness of the carbon fiber to evaluate the statistical significance of each parameter. Regarding surface roughness, none of the parameters studied displayed any significance, differing from the works by NorKhairusshima ${ }^{22}$, which affirms that the cutting speed and feed rate respectively follow inverse and direct relations. Analyzing the burrs, the tool cutting edge angle and combined effects of cutting depth with feed rate are determining factors. In general, the feed rate is the most important parameter in machining, followed by cutting speed. In this case, it didn't happen. Probably the combination of the machining parameters is not greater enough to make difference in the study. In the burr formation, the tool cutting edge angle was the most significant parameter, and these can be explained by Aurich ${ }^{12}$, because the $45^{\circ}$ tool cutting edge angle will generate smaller size burrs for the same cutting depth when comparing to the $90^{\circ}$ tool cutting edge, having greater influence in comparison to the other parameters. When $45^{\circ}$ tool cutting angle edge angle is used, the chip height in face milling is smaller as the tool advance in the exit of material. The same didn't happen with $90^{\circ}$ toll cutting angle edge, which will have a constant chip height along with the material. The burr formation according to Hashimura ${ }^{11}$ has eight stages: Continuous cutting, pre-initiation, initiation, pivoting, burr development, crack initiation, crack growth and positive burr (for ductile material) or negative burr (for brittle material). With smaller height, we have smaller chips in the pivoting point and consequently smaller burr will be formed.

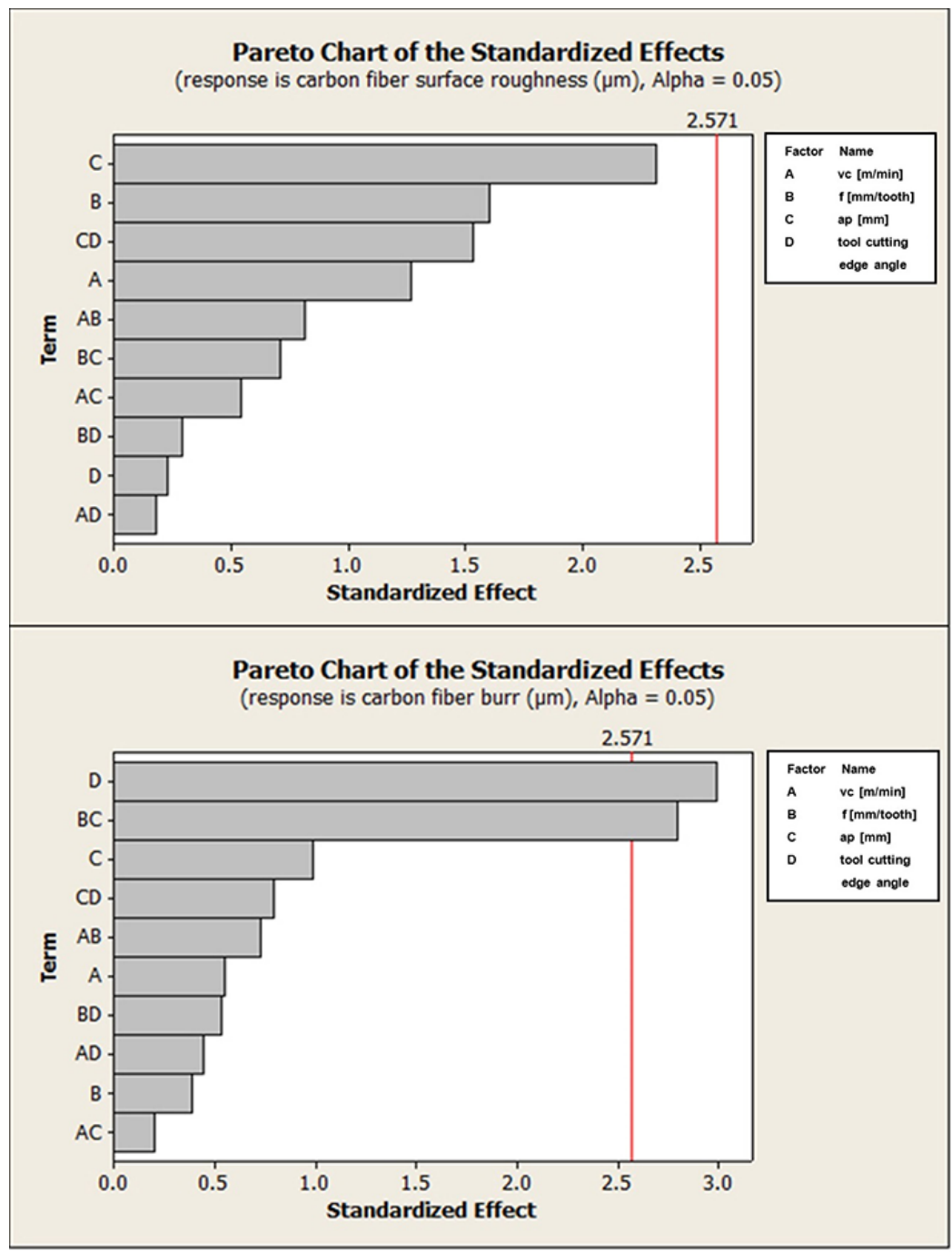

\section{Carbon fiber surface roughness}

(a)

\section{Carbon fiber burrs (b)}

Figure 4. Pareto charts for carbon fiber 
Figure 5 contains an interaction graph between the cutting depth and the feed rate along with the main effects of the tool cutting edge angle plot, both in relation to the carbon fiber burrs. The $45^{\circ}$ tool cutting edge angle can be stated to have generated burrs lower than $90^{\circ}$ and there is the presence of a strong crossword effect between the cutting depth and the feed rate. Probably with greater cutting parameters and consequently higher temperatures, the burr cutting was easier when compared with the smaller cutting parameters and bigger feed rates removed the burr in the base, in this way, the burr pivoting point in some cases was removed.

Regarding titanium, the Pareto charts in Figure 6 suggest that the evaluated factors presented statistical significance over surface roughness. The tool cutting edge angle was by far the most influential, followed by feed rate and the combined effects of both.
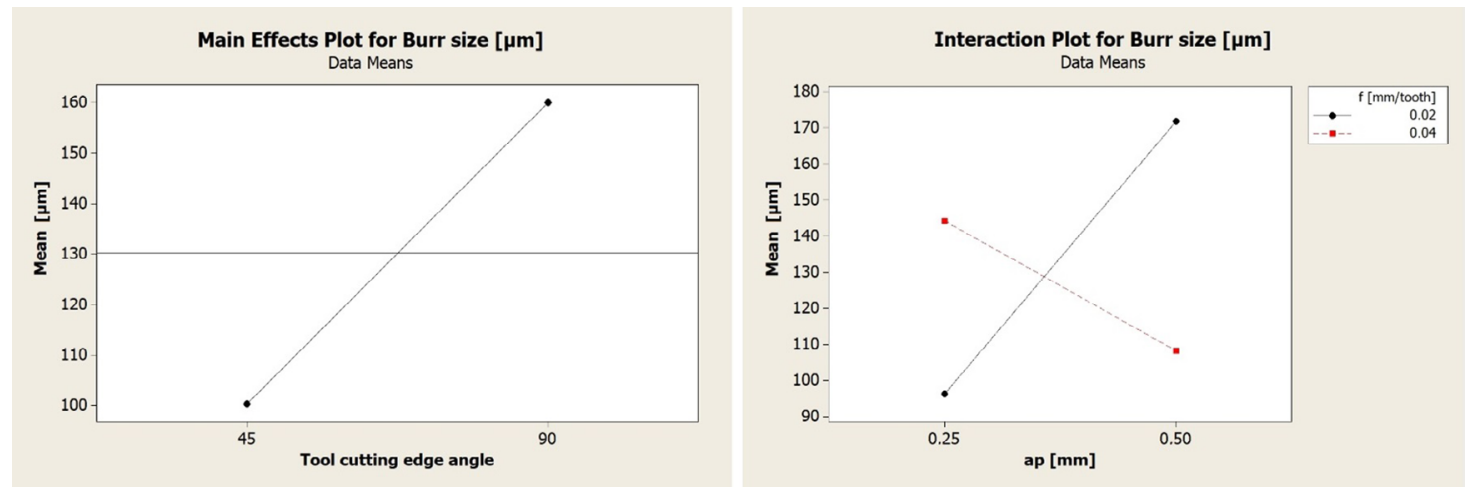

Figure 5. Main effects and interaction plots involving the determining factors for carbon fiber burrs

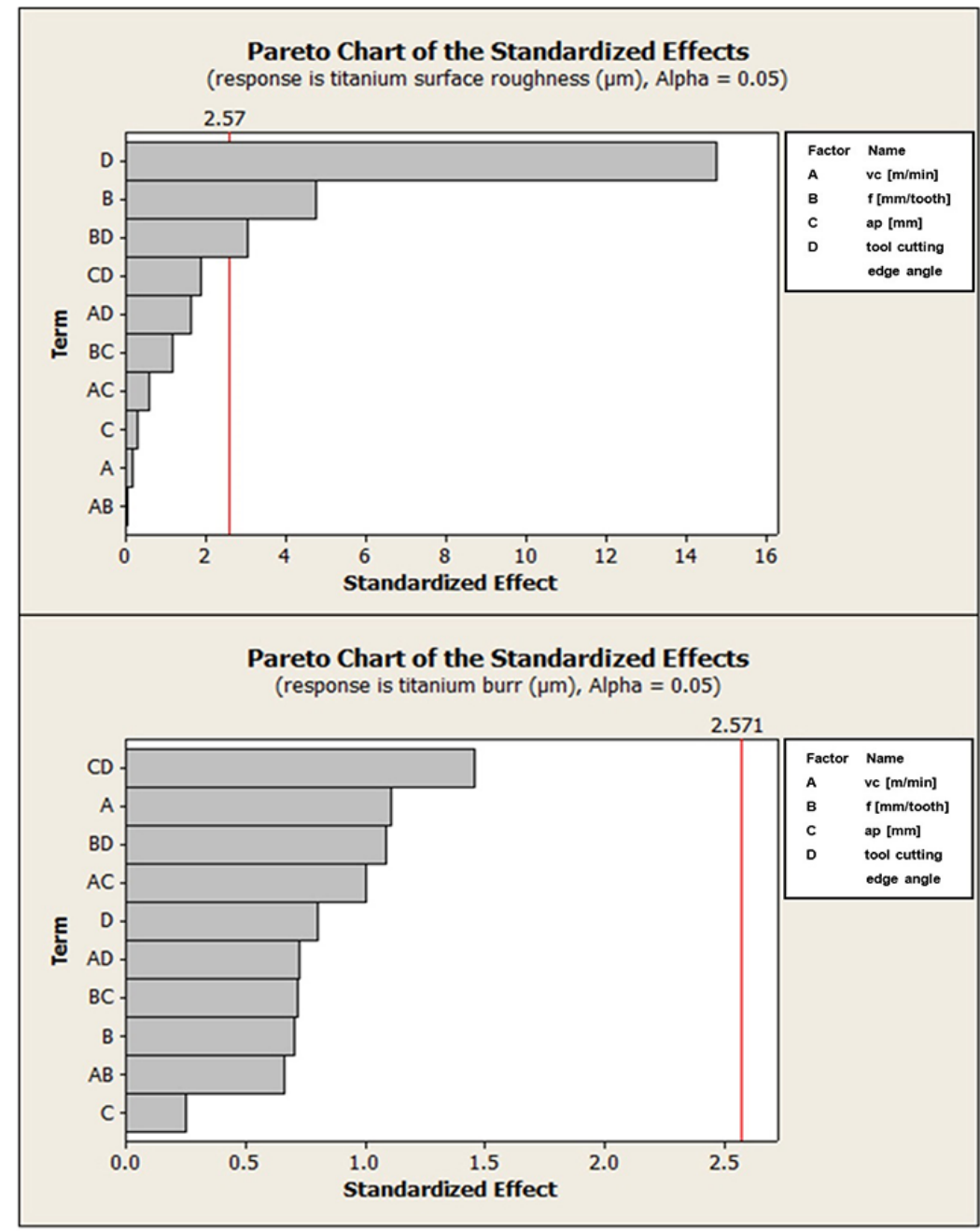

Titanium surface roughness

(a)

Titanium burrs (b)

Figure 6. Pareto charts for titanium burrs and surface roughness 
These observations are similar to the results from Bandapalli ${ }^{23}$, which affirms that tool cutting edge angle is the most influent, followed by feed rate. Usually, when only cutting parameters are analyzed, frequently the feed rate is the most important factor, as the roughness depends on geometrically from it. In this case, probably the vibration has affected the process, making the tool cutting edge angle the most important factor, considering the applied ranges.

Figure 7 presents the interactions between the cutting edge angle and the feed rate, and also the main effects of each plot over the titanium surface roughness. The main effects plot allows verifying that the tool cutting edge angle is directly proportional to the surface roughness of titanium and is the determining factor analyzed. The feed rate comes next, also directly proportional. The interaction graphs in Figure 7 propose that, for a $45^{\circ}$ tool cutting edge angle, the variance of surface roughness is almost zero among values of 0.02 and $0.04 \mathrm{~mm} /$ tooth for the feed rate. The longer contact with the tool cutting edge $=45^{\circ}$, probably induces smaller vibrations in the process, removing the ductile material in a better way. The smaller vibrations are connected to the smaller force in the radial direction and the higher force in the axial direction generated by the $45^{\circ}$ tool when compared to the $90^{\circ}$ tool. As the radial direction of the tool is not very rigid and the axial direction is, it is better to move the force components to the axial direction.

In Figure 8 and in Figure 9, contour graphs are presented for the elements (surface roughness and burr size), demonstrating the success for each material, considering statistical analysis. For a cutting speed of $180 \mathrm{~m} / \mathrm{min}$ (Figure 8), there were no factors in common for the carbon fiber burrs and titanium surface roughness to minimize both, since the materials are milled together. However, for a 150 $\mathrm{m} / \mathrm{min}$ cutting speed (Figure 9 ), this requirement was met. Therefore, the ideal parameters for minimizing burr size and surface roughness are: cutting speed of $150 \mathrm{~m} / \mathrm{min}, 45^{\circ}$ tool cutting edge angle, feed rate in the range of $0.026-0.028$ $\mathrm{mm} /$ tooth and cutting depth of $0.26 \mathrm{~mm}$.

From the analysis with the scanning electron microscope, delamination was observed on sample pieces belonging to trials 1,8 and 16 from Table 1. Figure 10 displays the results from the three. Most of the samples in which delamination was observed were milled with a cutting speed of $180 \mathrm{~m} / \mathrm{min}$, contradicting the work by NorKhairusshima ${ }^{22}$ : the delamination rate follows an inversely proportional relation. However, it should be emphasized that delamination strongly depends on the fiber orientation and feed rate direction ${ }^{24}$ and, as previously said, not all sample pieces were verified.

Figure 11 presents the resulting burrs from titanium and carbon fiber milling. The titanium burrs are typical for a metal: highly irregular and very deformed. In contrast, carbon fiber burrs are ruptures on its strings, similar to a ripped fabric.

In Figure 12, there are titanium burrs obtained by metallography. Pieces 24 and 32 were machined using the same parameters with the exception of the burr-formation region (or material), while 17 and 27 differ in feed rate and material.
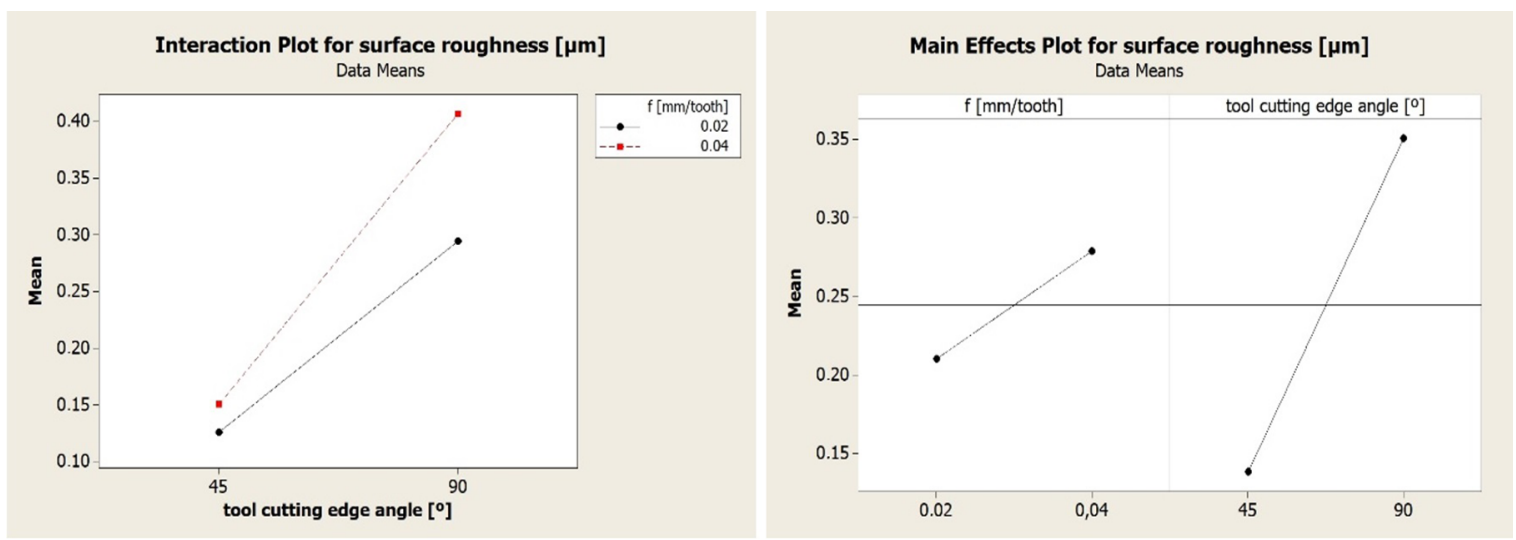

Figure 7. Main effects and interaction plots involving the determining factors for titanium surface roughness 


\section{Contour Plot of Burr size $[\mu \mathrm{m}]$ vs ap $[\mathrm{mm}] ; \mathbf{f}[\mathrm{mm} /$ tooth $]$}

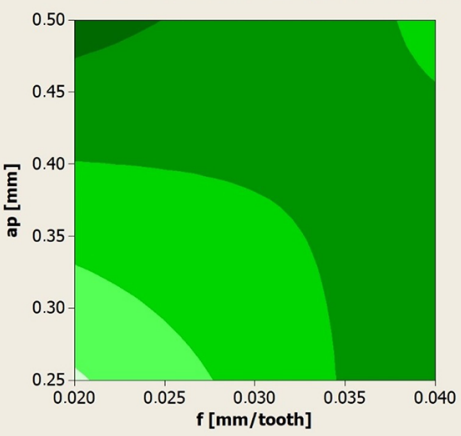

Contour Plot of surface roughness $[\mu \mathrm{m}]$ vs ap $[\mathrm{mm}] ; \mathbf{f}[\mathrm{mm} /$ tooth $]$

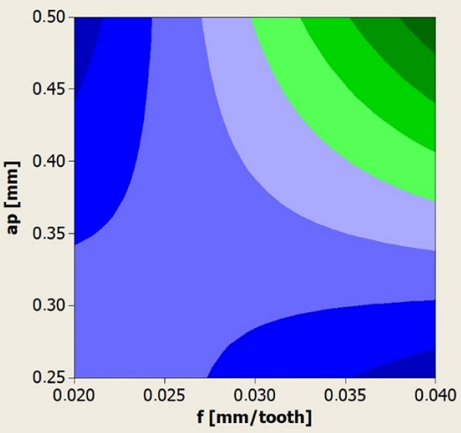

Figure 8. Contour plots for carbon fiber burrs and titanium surface roughness, $(\mathrm{vc}=180 \mathrm{~m} / \mathrm{min})$
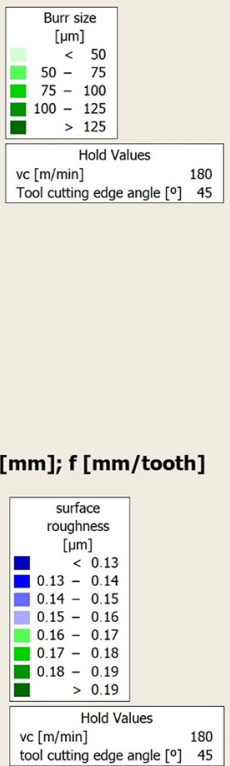

45
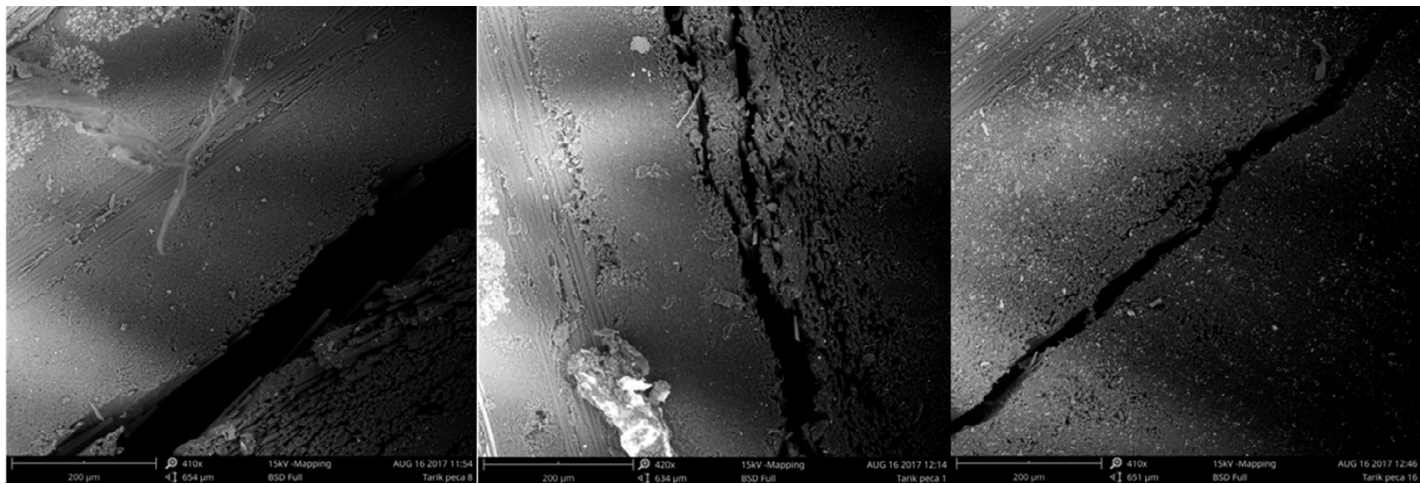

Figure 10. Occurrence of delamination on sample pieces 1, 8 and 16 (from left to right)
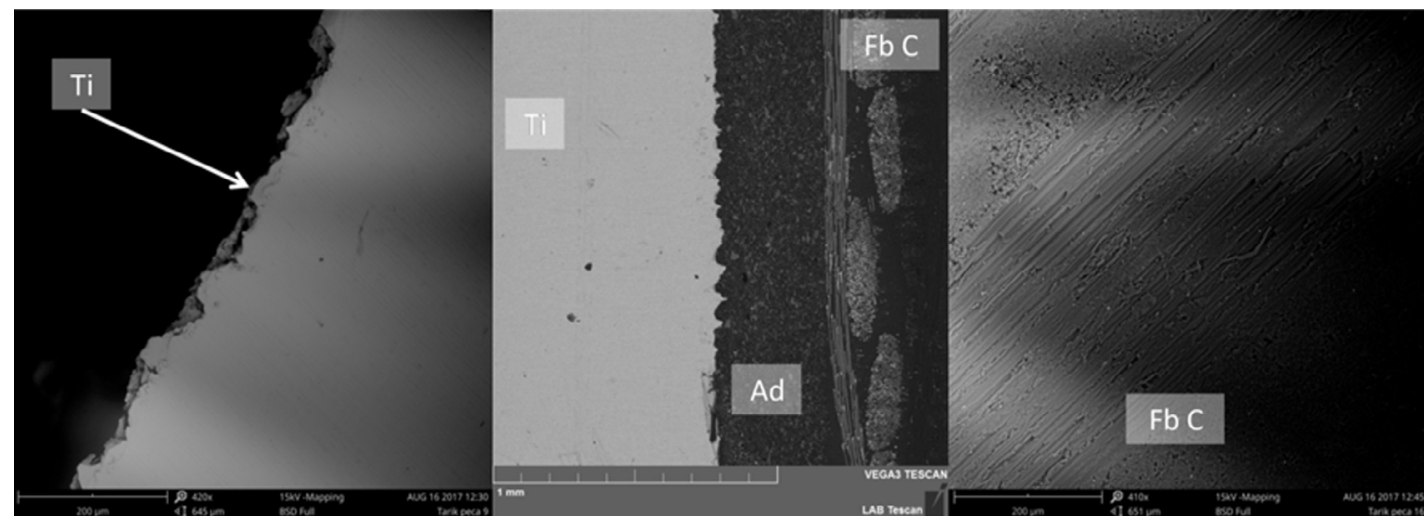

Figure 11. Resulting burrs from machining trials. On the left, titanium (a), center: titanium, adhesive and carbon fiber (b); and right: carbon fiber. Subtitles: $\mathrm{Ti}$ - titanium, $\mathrm{Fb} \mathrm{C}$ - carbon fiber and $\mathrm{Ad}$ - adhesive. Images obtained by scanning electron microscopy 


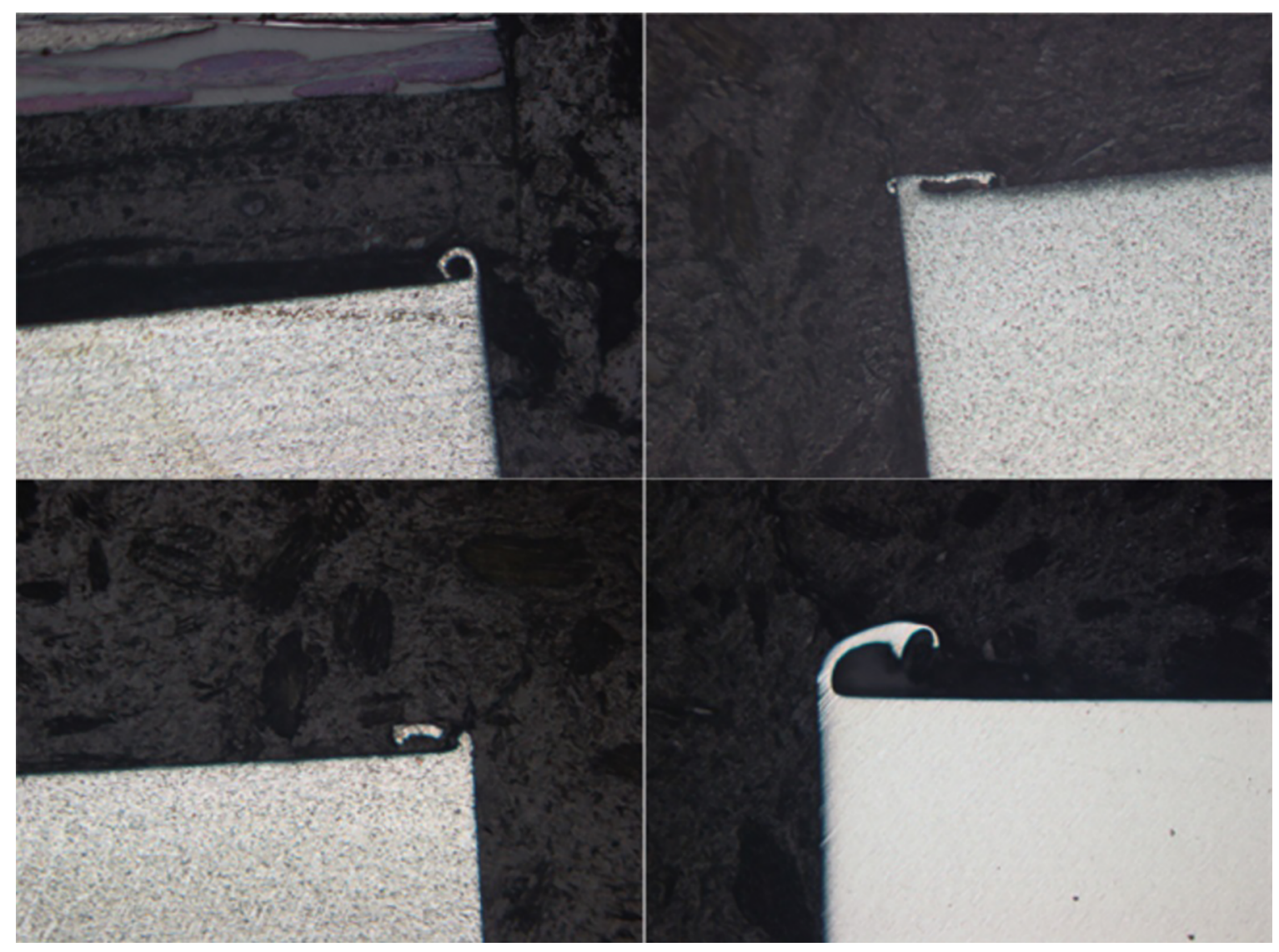

Figure 12. Burrs on sample pieces 17 (a), 24 (c), 27 (b) and 32 (d). Images obtained through optical microscopy

\section{Conclusions}

The results analyses showed that, regarding carbon fiber, the surface roughness measured were in the range of 0.38 and $1.65 \mu \mathrm{m}$ and burr in 38 and $210 \mu \mathrm{m}$. To obtain the lowest surface roughness and burr, the parameters used were: $\mathrm{v}_{\mathrm{c}}=150$ $\mathrm{m} / \mathrm{min}, \mathrm{f}=0.02 \mathrm{~mm} /$ tooth, $\mathrm{a}_{\mathrm{p}}=0.25 \mathrm{~mm}$, tool cutting edge angle $=45^{\circ}$ and the material was carbon fiber. The surface roughness did not present factors with statistical significance, whereas burr formation had the tool cutting edge angle and combined effects of cutting depth and feed rate as determining.

In turn, the surface roughness obtained for titanium was in the range of $0.0917 \mu \mathrm{m}$ and $0.5800 \mu \mathrm{m}$ and for burrs, 66.5 and $2680 \mu \mathrm{m}$. The parameters used to obtain the lowest surface roughness were $\mathrm{v}_{\mathrm{c}}=180 \mathrm{~m} / \mathrm{min}, \mathrm{f}=0.04 \mathrm{~mm} /$ tooth, $\mathrm{a}_{\mathrm{p}}=0.25 \mathrm{~mm}, 45^{\circ}$ tool cutting edge angle and carbon fiber as the material; and for the lowest burrs: $\mathrm{v}_{\mathrm{c}}=180 \mathrm{~m} / \mathrm{min}, \mathrm{f}=0.02$ $\mathrm{mm} /$ tooth, $\mathrm{a}_{\mathrm{p}}=0.25 \mathrm{~mm}$, tool cutting edge angle $=45^{\circ}$ and carbon fiber as the material.

To minimize the titanium surface roughness and carbon fiber burrs, the recommendation is using a tool cutting edge angle $=45^{\circ}$, feed rate $=0.028 \mathrm{~mm} /$ tooth, maximum cutting depth of $0.26 \mathrm{~mm}$ and $150 \mathrm{~m} / \mathrm{min}$ cutting speed.
The delamination rate shared an inversely proportional relationship with the cutting speed, even though most pieces analyzed that suffered delamination, had been milled with the maximum cutting speed.

\section{Acknowledgments}

The authors would like to thank the Maua Institute of Technology and Sandvik Coromant for the sponsorship of this work.

\section{References}

1. Wulfsberga J, Herrmannb A, Ziegmannc G, Lonsdorferb G, Stößd N, Fette M. Combination of carbon fibre sheet moulding compound and prepreg compression moulding in aerospace industry. Procedia Engineering. 2014;81:1601-1607.

2. Rezende MCO. Uso de compósitos estruturais na indústria aeroespacial. Polímeros. 2000;10(2):e4-e10.

3. Denkena B, Boehnke D, Dege JG. Helical milling of CFRPtitanium layer compounds. CIRP Journal of Manufacturing Science and Technology. 2008;1(2):64-69. 
4. Dahnel AN, Ascroft H, Barnes S. The effect of varying cutting speeds on tool wear during conventional and Ultrasonic Assisted Drilling (UAD) of Carbon Fibre Composite (CFC) and titanium alloy stacks. Procedia CIRP. 2016;46:420-423.

5. Trent EM, Wright PK. Metal cutting. $4^{\text {th }}$ ed. Woburn: ButterworthHeinemann; 2000.

6. Ozkan D, Gok MS, Oge M, Karaoglanli CA. Milling behavior analysis of carbon fiber-reinforced polymer (CFRP) composites. Materials Today: Proceedings. 2019;11(Pt 1):526-533. DOI: https://doi.org/10.1016/j.matpr.2019.01.024

7. Karataş MA, Gökkaya H. A review on machinability of carbon fiber reinforced polymer (CFRP) and glass fiber reinforced polymer (GFRP) composite materials. Defence Technology. 2018;14(4):318-326. DOI: https://doi.org/10.1016/j.dt.2018.02.001

8. Klotz S, Zanger F, Schulze V. Influence of clamping systems during milling of carbon fiber reinforced composites. Procedia CIRP. 2014;24:38-43.

9. Melentiev R, Priarone PC, Robiglio M, Settineri L. Effects of tool geometry and process parameters on delamination in CFRP drilling: an overview. Procedia CIRP. 2016;45:31-34.

10. Kurniawan R, Kumaran ST, Prabu VA, Zhen Y, Park KM, Kwak YI, et al. Measurement of burr removal rate and analysis of machining parameters in ultrasonic assisted dry EDM (US-EDM) for deburring drilled holes in CFRP composite. Measurement: Journal of the International Measurement Confederation. 2017;110:98-115. DOI: https://doi.org/10.1016/j.measurement.2017.06.008

11. Hashimura M, Hassamontr J, Dornfeld DA. Effect of in-plane exit angle and rake angles on burr height and thickness in face milling operation. Journal of Manufacturing Science and Engineering. 1999;121(1):13. DOI: https://doi.org/10.1115/1.2830566

12. Aurich JC, Dornfeld D, Arrazola PJ, Franke V, Leitz L, Min S. Burrs-analysis, control and removal. CIRP Annals. 2009;58(2):519542. DOI: https://doi.org/10.1016/j.cirp.2009.09.004

13. Rajmohan T, Palanikumar K, Davim JP. Analysis of surface integrity in drilling metal matrix and hybrid metal matrix composites. Journal of Materials Science and Technology. 2012;28(8):761768. DOI: https://doi.org/10.1016/S1005-0302(12)60127-3

14. Erkan $\boldsymbol{O}$, Isik B. Investigation of cutting parameter effects on surface roughness during machining of glass fiber reinforced plastic composite material. In: $5^{\text {th }}$ International Advanced Technologies Symposium; 2009 may 13-15; Karabük, Tuerkey. Karabük: IATS 09; 2009. p. 1412-1419.
15. Morine MR. Machining in stack of fiber carbon and titanium with polycrystalline diamond $(P C D)$ drill [thesis]. São Caetano do Sul (SP): Maua Institute of Technology; 2016.

16. Kumar P, Kumar M, Bajpai V, Singh NK. Recent advances in characterization, modeling and control of burr formation in micro-milling. Manufacturing Letters. 2017;13:1-5.

17. Thepsonthi T, Özel T. Multi-objective process optimization for micro-end milling of Ti-6Al-4V titanium alloy. The International Journal of Advanced Manufacturing Technology. 2012;63:903-914.

18. Thepsonthi T, Özel T. An integrated toolpath and process parameter optimization for high-performance micro-milling process of Ti-6Al-4V titanium alloy. The International Journal of Advanced Manufacturing Technology. 2014;75:57-75.

19. Ali MH, Khidhir BA, Ansari MNM, Bashir M. FEM to predict the effect of feed rate on surface roughness with cutting force during face milling of titanium alloy. HBRC Journal. 2013;9(3):263269. DOI: https://doi.org/10.1016/j.hbrcj.2013.05.003

20. Karkalos NE, Galanis NI, Markopoulos AP. Surface roughness prediction for the milling of Ti-6Al-4V ELI alloy with the use of statistical and soft computing techniques. Measurement. 2016;90:25-35. DOI: https://doi.org/10.1016/j. measurement.2016.04.039

21. Shokrani A, Dhokia V, Newman ST. Investigation of the effects of cryogenic machining on surface integrity in $\mathrm{CNC}$ end milling of Ti-6Al-4V titanium alloy. Journal of Manufacturing Processes. 2016;21:172-179. DOI: https://doi.org/10.1016/j. jmapro.2015.12.002

22. Nor Khairusshima MK, Aqella AKN, Sharifah ISS. Optimization of milling carbon fibre reinforced plastic using RSM. Procedia Engineering. 2017;184:518-528.

23. Bandapalli C, Sutaria BM, Bhatt DV, Singh KK. Experimental investigation and estimation of surface roughness using ANN, GMDH \& MRA models in high speed micro end milling of titanium alloy (grade-5). Materials Today: Proceedings. 2017;4(2 Pt A):1019-1028.

24. Voss R, Seeholzer L, Kuster F, Weneger K. Influence of fibre orientation, tool geometry and process parameters on surface quality in milling of CFRP. CIRP Journal of Manufacturing Science and Technology. 2017;18:75-91. 